\title{
The Effects of the Big Five Personality Traits on Stress among Robot Programming Students
}

\author{
Anita Pollak ${ }^{1, *(\mathbb{D})}$, Małgorzata Dobrowolska ${ }^{2}$ (I) , Anna Timofiejczuk ${ }^{3}$ and Mateusz Paliga ${ }^{1}$ (i) \\ 1 Faculty of Social Sciences, University of Silesia in Katowice, 40-126 Katowice, Poland; \\ mateusz.paliga@us.edu.pl \\ 2 Institute of Education and Communication Research, Silesian University of Technology, \\ 44-100 Gliwice, Poland; malgorzata.dobrowolska@polsl.pl \\ 3 Faculty of Mechanical Engineering, Silesian University of Technology, 44-100 Gliwice, Poland; \\ anna.timofiejczuk@polsl.pl \\ * Correspondence: anita.pollak@us.edu.pl
}

Received: 4 May 2020; Accepted: 24 June 2020; Published: 25 June 2020

check for updates

\begin{abstract}
This paper presents relationships between personality traits and stress levels in light of the transactional model of stress. The framework of the transactional model was applied to determine the significance of work with a robot for primary and secondary stress appraisal made by an individual. We decided to use the Big Five personality traits model as one which integrates the dimensions of personality and had been previously applied to research on stress. The participants in our three-wave study were 105 students doing an industrial robots programming course. Using Ten Item Personality Inventory (TIPI) and Questionnaire for Primary and Secondary Appraisal (PASA) questionnaires, we gathered information about the students' personality, the level of anticipated stress, and the stress experienced while working with a robot after 6 and 12 weeks. The obtained results prove that emotional stability is significant for secondary appraisal of anticipated stress. The results also show that openness to experience is a negative predictor, whereas conscientiousness is a positive predictor of primary stress appraisal. The ability to cope with stress after 12 weeks of work with a robot is appraised as higher by older, more conscientious, and introverted people. The obtained results are discussed from the psychological perspective of stress and personality, which complements earlier studies in technical sciences. The limitations of the study are also indicated.
\end{abstract}

Keywords: The Big Five; stress; primary stress appraisal; secondary stress appraisal; human-robot interaction

\section{Introduction}

The use of robots in Industry 4.0 is constantly increasing, allowing for better optimisation of manufactures [1]. Industrial robots are used to create "adaptable, reconfigurable, and sustainable production systems, which consider the human as their core and valuable part" [2] (p. 1).

The implementation of modern technologies at work is accompanied by a debate on the threats they bring [3] and ways of guaranteeing their human operators' safety [4]. Two particularly important issues in the debate are those of physical and psychological safety. The former is ensured by avoiding direct contact between the human and the robot or by using the lowest levels of robot power when the contact is necessary [4]. Psychological security concerns the fact that robots should neither scare or surprise humans nor dissatisfy them [5] or induce stress through the robot's appearance, gaze, speech or sounds, posture or other qualities $[4,6]$.

Therefore, stress evaluation is a key requirement for human-robot interaction. It should be based on an analysis of the physiological and psychological qualities of human beings and the stress 
they experience [7]. Monitoring the states experienced by people in contact with robots enhances the safety of this interaction, the wellbeing of the operator, and enables a more sustainable and better development, planning, and monitoring of the robots [8,9]. The above spurred us to undertake research on the effects of personality traits on stress. The aim of the research was to determine whether the personality traits of the Big Five model [10] are predictors of stress defined in the transactional theory [11]. The research was conducted from the perspective of psychology, which-according to Bartneck, Kulić, Croft and Zoghbi [12]—Constitutes a valuable complement for considerations undertaken in the field of technical sciences.

\section{Theoretical Background and Hypotheses}

\subsection{Transactional Model of Stress}

The concept developed by Lazarus and Folkman [11] accentuates the appraisal of the interactions between the individual and the environment. As they happen, events become subjects of cognitive interpretation performed by the individual. The individual, in constant transactions with the environment, performs such interpretation in light of external requirements and their own abilities. The appraisal process consists of two stages. In primary appraisal, the person refers to the significance of a given situation to themselves. Some situations may be positive or irrelevant, while others may be stressful. The latter is the case when the individual assesses the situation as a loss, a threat, or a challenge. A threat is a situation in which the individual assesses their abilities to cope with stress as insufficient, while in the case of a challenge, the individual finds themselves capable of coping with the requirements of the situation [13]. In secondary appraisal, the individual assesses the chances of coping with the requirements of the situation, basing the assessment on their own abilities and the control they have. There is a difference between the appraisal of a current situation, which the individual bases on their self-concept of own abilities and their control expectancy, and the appraisal of potential loss predicted by the individual to result from stressful situations occurring in the future, on which the individual does not have influence [14]. Based on primary and secondary appraisal, the individual undertakes actions aimed at coping with stress $[15,16]$.

\subsection{The Big Five Personality Model}

Personality is an important concept in discussions of stress [16-18]. It determines how individuals assess a situation as a harm, a threat, or a challenge [19]. Among the personality concepts developed so far [20], the Big Five model [21] is considered to be the most universal. It has been praised for integrating and ordering dimensions of personality and a matrix of traits supported by cross-cultural research [22]. Moreover, the model conforms with self-description and observational data $[20,23]$ and has been used as a theoretical framework in human-robot interaction studies focused on the role of the personality of robot operators [24].

In the Big Five model, the structure of personality consists of the following dimensions: (a) extraversion; (b) emotional stability (vs. neuroticism); (c) openness to experience; (d) agreeableness; (e) conscientiousness [10]. Extraversion refers to the social dimension of functioning and defines the amount and quality of social interaction, as well as the level of activity, energy, and ability to feel positive emotions. Emotional stability is understood as an individual's lack of susceptibility to experiencing negative emotional states, such as fear, anger, irritation, or guilt. Openness to experience is a dimension related to an individual's tendency to search for life experience and evaluate it positively. Moreover, it involves cognitive curiosity and tolerance for novelty. It is also related to divergent thinking and creativity. Agreeableness is a dimension describing an interpersonal orientation manifesting itself in altruism or antagonism. In behaviour, the former means being sensitive to others, trusting them, and being willing to cooperate. The latter, on the contrary, means indifference to others, lack of trust, and competitiveness. Conscientiousness refers to the level of organisational skills, persistence, and an individual's motivation in goal-oriented actions [10,25]. Low extraversion scores correlate to 
manifestations of reserve in contacts with others and lower willingness to seek social support [26]. O'Brien and DeLongis [27] prove that persons with high extraversion apply a coping strategy based on the rejection of responsibility for the occurrence of a stress-related situation. Neuroticism presents the strongest links with stress $[16,17,28]$. Since neuroticism is related to negative emotionality, it often causes persons to experience negative emotions which tend to linger for a long time. Consequently, such persons evaluate the situation as a loss or threat. In the process of secondary stress appraisal, persons high in neuroticism do not appreciate their own resources for coping with stress [29]. Results of studies on highly agreeable people indicate that the positive attitude they manifest correlates with a smaller amount of social conflicts and with more support received from others [30]. Thanks to such components as competence, prudence, and dutifulness, conscientiousness can be a protective buffer against stress in sudden or chronic situations [16,31]. However, because of their perfectionism, highly conscientious persons assess the situation as stressful more often. This is caused by the fact that they feel the pressure to achieve good results [25,32]. When coping with stress, instead of avoiding it, conscientious persons undertake direct remedial actions [13]. The research done so far does not provide consistent findings of relations between openness to experience and stress [16,18].

\subsection{The Importance of Stress and Personality in Human-Robot Interaction}

According to Taniguchi et al. [7], in order to improve Human-Robot Interaction (HRI), it is necessary not only to develop robots' intelligence and physical abilities but also to find a way to evaluate stress experienced by people in this interaction. As a matter of fact, there is a number of studies on stress providing analyses of humans' cognitive, emotional, and physiological reactions to robots.

Nonaka, Inoue, Arai, and Mae [33] measured heart rate and cognitive-affective reactions (surprise, fear, disgust, and unpleasantness) in 23 persons watching virtual depictions of a robot. They found a correlation between the speed of the robot and the fear and surprise experienced by the participants. In another study, Inoue, Nonaka, Ujiie, Takubo, and Arai [5] used a semantic differential and demonstrated, in a group of 13 men, that visual impressions and psychological states experienced with virtual and real robots are similar. A limitation of the study is the fact that the analyses are conducted in a correlative model and not in a differential one.

Kulić and Croft [34] conducted an experiment with 10 persons. They measured physiological reactions to a robot's movement (heart muscle activity, skin conductance, and corrugator muscle activity) as well as emotional ones (anxiety, calm, and surprise). The results they obtained showed that respondents reported less anxiety when safe, planned motions were presented. In another study, Kulić and Croft [8] used the same variables and obtained, in a group of 36 participants, results demonstrating a positive correlation between anxiety and speed as well as between surprise and speed but a negative correlation between calm and speed. Moreover, the subjects felt less anxious and surprised but calmer when the robot operated in the safe planner mode compared to the conventional potential field planner mode.

Bartneck, Kulić, Croft, and Zoghbi [12] found user satisfaction to be a performance criterion of service for robots. They created their own semantic differential to study satisfaction in a wide, six-dimensional approach. The dimension of perceived safety contains questions concerning being anxious-relaxed, agitated-calm, and quiescent-surprised on a 1-5 scale. However, we perceive a certain inaccuracy in the design of this dimension, namely the lack of suitable valence/arousal emotional model for opposite adjectives in the last pair.

The subject of Arai, Kato, and Fujita's research [35] was physiological and psychological strain (i.e., fear, surprise, and discomfort). Applying skin conductance response measurements and a semantic differential, the authors proved that the cooperating robot should be located two metres away from the worker and should be moving at a speed of $500 \mathrm{~mm} / \mathrm{s}$. Such settings protect the human operator of the robot against experiencing physiological stress and the subjective feelings of fear and surprise. Moreover, the level of the employee's physiological stress and surprise decreases after they have been informed about the speed of the robot's movement. 
Another example is the research conducted by Dekker, Salomons, and Waal [3], performed on the Eurobarometer Public Attitudes towards Robots dataset. The authors used the Fear of Robots at Work questionnaire and obtained results proving that the fear of robots in 2012 was average. A greater fear was characteristic of less educated and unemployed persons and blue-collar workers. Otherwise, the higher in the hierarchy the persons were and the more professional they were, the less fear they declared.

The premise of personality theories in HRI is that human traits can determine the presence or absence and the quality of the interaction between the robot and its human operator [24]. To the best of our knowledge, only one study so far has discussed the issues of personality and stress in HRI. Takayama and Pantofaru [36] conducted an experiment in which, with a group of 30 participants, they proved that agreeable individuals moved closer to a robot, whereas highly neurotic persons (ones with low emotional stability) maintained greater distance both from a teleoperated robot and from an approaching autonomous robot. Since the stress experienced by the participants may be related to increasing distance from the stressor (e.g., the fight-or-flight response), the study is an important premise for the present paper.

Despite the significant research results concerning objective and subjective reactions to a robot, no analysis so far has been conducted using transactional stress theory and the Big Five model of personality traits. These theories are valuable psychological complements for technical studies and enable an application of validated tools, which in turn enable comparisons between groups and replication of studies. For this reason, and taking into account the analysis conducted so far, we propose the following hypotheses:

Hypothesis 1 (H1). Extraversion, emotional stability, openness to experience, and agreeableness are negative predictors of primary stress appraisal, and conscientiousness is a positive predictor of primary stress appraisal.

Hypothesis 2 (H2). Extraversion, emotional stability, openness to experience, agreeableness, and conscientiousness are positive predictors of secondary stress appraisal.

\section{Materials and Methods}

\subsection{Sample and Procedure}

There were 105 participants in the study, of whom 86 (81.9\%) were men. The subjects were aged 21-26 $(M=22.06 ; S D=0.80)$. All participants were students of the Silesian University of Technology, studying Mechanics and Machine Design (48.6\%), Mechatronics (33.3\%), and Production Engineering and Management (18.1\%). Study participants were fourth-year students who had to complete the mandatory classes in automation and robotization. These were the first project-based classes in the study program, during which the students were commissioning and programming several types of robots of different brands. The general aim of the classes was point-to-point and continuous path on-line programming. The particular aims included programming of the work sequence of the robot, triggering the sub-programs, checking and improving the program in terms of the safety and efficiency of work, starting the robot in the supervised mode, making changes in positioning and optimising performance, bringing the robot out of the emergency state, checking the correctness of the program, and the efficiency of the robot in automatic mode. None of the participants had familiarity with industrial robots before the course. Participation in the study was voluntary. The participants did not receive any compensation for their participation.

The study procedure assumed measurement in three waves. The first study (T1) was conducted at the second meeting of the course. The subjects were asked to assess (1) the level of stress they predicted to appear in their future performance of tasks using robots and (2) the behavioural manifestations of their personality traits in accordance with the Big Five model. The second study (T2) took place 6 weeks after the first one. In its course, the participants assessed the level of stress they had experienced while performing tasks with a robot for the previous 6 weeks. The third stage (T3) took place after the next 
6 weeks, and the level of stress after another 6 weeks of work with the robot was assessed then. At each stage, the data were collected at the beginning of the class.

This research project received a favourable opinion from the University of Silesia Ethics Committee on scientific research involving humans (no. KEUS.20/04.2020). All participants expressed consent to take part in the study, which was executed in accordance with the guidelines of the Declaration of Helsinki.

\subsection{Measures}

The primary and secondary appraisals of stress were measured with the shortened version of the Questionnaire for Primary and Secondary Appraisal (PASA) [14]. This 4-item tool is intended for self-description, which the subject performs using a scale of responses from 1 (strongly disagree) to 6 (strongly agree). The tool consists of two scales: primary and secondary appraisal, which together create a global scale of stress appraisal. Pearson inter-item correlations between two primary scale items were $\mathrm{r}_{\mathrm{T} 1}=0.32 ; \mathrm{r}_{\mathrm{T} 2}=0.39 ; \mathrm{r}_{\mathrm{T} 3}=0.19$, which is an acceptable result, confirming homogeneity of the scale [37]. In the case of secondary appraisal, the reliability of the scale was satisfactory and reached to $\alpha_{\mathrm{T} 1}=0.81 ; \alpha_{\mathrm{T} 2}=0.84 ; \alpha_{\mathrm{T} 3}=0.70$.

Personality traits were measured with the Ten Item Personality Inventory (TIPI) [38]. The inventory enables measuring the Big Five model personality traits by means of self-description, which the subject performs using a scale of responses from 1 (strongly disagree) to 7 (strongly agree). The reliability of the scales of extraversion $(\alpha=0.75)$, emotional stability $(\alpha=0.44)$, openness to experience $(\alpha=0.69)$, and agreeableness $(\alpha=0.53)$ was acceptable [38,39]. In the case of conscientiousness, reliability was low $(\alpha=0.32)$, but Pearson inter-item correlation for two items of the scale showed acceptable homogeneity $(r=0.19)$. Due to the high content validity of the scale, the obtained results are satisfactory [39].

\section{Results}

\subsection{Descriptive Statistics}

Table 1 presents the results of descriptive statistics and the Kolmogorov-Smirnov distribution normality test. The studied group is characterised by a moderate level of extraversion, emotional stability, openness to experience, agreeableness, and conscientiousness. At the first point in time, the subjects anticipated that work with a robot would be moderately stressful for them and they would be able to cope with it moderately well. Stress appraisals at the other two points in time (T2 and T3) were similar: both the primary and the secondary stress appraisal results were moderate.

Table 1. Descriptive statistics.

\begin{tabular}{|c|c|c|c|c|c|c|}
\hline \multirow{2}{*}{ Variable } & \multirow{2}{*}{ Mean } & \multirow{2}{*}{ SD } & \multirow{2}{*}{ Min } & \multirow{2}{*}{$\operatorname{Max}$} & \multicolumn{2}{|c|}{ Kolmogorov-Smirnov $(\mathrm{df}=105$} \\
\hline & & & & & Statistic & Sig. \\
\hline Extraversion & 5.43 & 1.36 & 1 & 7 & 0.18 & $<0.05$ \\
\hline Emotional Stability & 4.86 & 1.22 & 2 & 7 & 0.14 & $<0.05$ \\
\hline Openness to Experience & 4.79 & 1.04 & 2.5 & 7 & 0.11 & $<0.05$ \\
\hline Agreeableness & 5.16 & 1.01 & 2.5 & 7 & 0.11 & $<0.05$ \\
\hline Conscientiousness & 5.27 & 1.18 & 2 & 7 & 0.21 & $<0.05$ \\
\hline Primary Appraisal (T1) & 3.35 & 1.07 & 1 & 6 & 0.11 & $<0.05$ \\
\hline Primary Appraisal (T2) & 3.19 & 1.01 & 1 & 6 & 0.14 & $<0.05$ \\
\hline Primary Appraisal (T3) & 3.21 & 1.03 & 1 & 6 & 0.12 & $<0.05$ \\
\hline Secondary Appraisal (T1) & 4.18 & 1.09 & 1.5 & 6 & 0.18 & $<0.05$ \\
\hline Secondary Appraisal (T2) & 4.14 & 0.96 & 1 & 6 & 0.12 & $<0.05$ \\
\hline Secondary Appraisal (T3) & 4.20 & 1.11 & 1 & 6 & 0.13 & $<0.05$ \\
\hline
\end{tabular}




\subsection{Correlation Analysis}

Due to the lack of distribution normality of all the variables (Table 1), the correlation analysis was performed using the Spearman nonparametric measure of rank correlation. The correlation coefficients shown in Table 2 point to moderate and weak positive correlations of extraversion with all personality traits in the Big Five model. Emotional stability correlates positively and weakly with openness to experience and conscientiousness. Conscientiousness is in a weak positive correlation with agreeableness. The analysis of relations between the primary and secondary stress appraisals at three points in time reveals that the primary stress appraisal in T1 is positively and weakly correlated with the primary appraisal in T2, and negatively and weakly correlated with the secondary appraisal in T1. Moreover, the primary stress appraisal in T3 is positively and weakly related to the secondary stress appraisal in T3. Regarding the relationships of personality traits and primary and secondary stress appraisal, emotional stability correlates positively and weakly with the secondary stress appraisal in T1, and openness to experience correlated negatively and weakly with the primary stress appraisal in T2.

Table 2. Spearman rank-order correlation coefficients for studied variables.

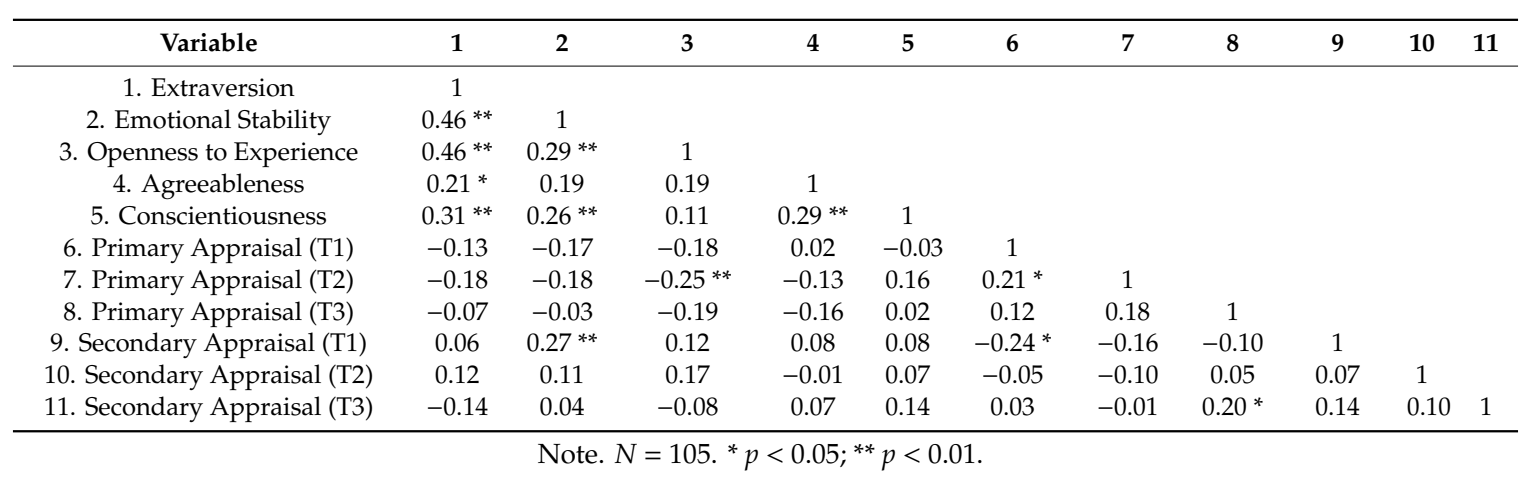

Moreover, we calculated statistics of collinearity for personality variables, which will be used as predictors in regression analysis. VIF did not exceed 1.58 for any of the variables, indicating no collinearity between them [40].

\subsection{Regression Analysis}

Tables 3 and 4 present the results of the verification of the hypotheses. Models of regression were created for three points in time (T1, T2, and T3) for two dependent variables (primary and secondary stress appraisal). In each Model 1, control variables (gender and age) were included in regression models. In each Model 2, independent variables (five personality traits in the Big Five model) were added to the control variables.

Table 3 presents the results for hypothesis $\mathrm{H} 1$ about the predictive role of the Big Five traits for primary stress appraisal. No model 1, including the control variables, shows a good fit. Among the model 2s, only in the case of the T2 point in time is the regression significant. Openness to experience is an important negative predictor of primary stress appraisal, whereas conscientiousness is its positive predictor. The inclusion of personality traits in the model results in a significant change of the explained variance, reaching $15 \%$, and the entire model explains the $9 \%$ variance of primary stress appraisal.

Table 4 presents the results of the testing of hypothesis $\mathrm{H} 2$ about the predictive roles of personality traits for secondary stress appraisal. Among the control variables included in Model 1, age proved to be a significant positive predictor in T2. This model provides explanation for the $5 \%$ variance of secondary stress appraisal. Adding independent variables (personality traits) to the model causes a significant $10 \%$ increase of the explained variance in $\mathrm{T} 1$, proving that emotional stability is a significant positive predictor of secondary stress appraisal. In the case of model 2 in T3, adding independent variables does not significantly change the percentage of explained variance. However, Model 2 of regression 
is significant and explains the $8 \%$ of dependent variable. Age and conscientiousness are positive predictors of secondary stress appraisal in this model, whereas extraversion is its negative predictor.

Table 3. Hierarchical regression analyses of The Big Five personality traits as predictors of Primary Stress Appraisal.

\begin{tabular}{|c|c|c|c|c|c|c|}
\hline \multirow{3}{*}{ VARIABLES } & \multicolumn{2}{|c|}{ Primary Appraisal (T1) } & \multicolumn{2}{|c|}{ Primary Appraisal (T2) } & \multicolumn{2}{|c|}{ Primary Appraisal (T3) } \\
\hline & Model 1 & Model 2 & Model 1 & Model 2 & Model 1 & Model 2 \\
\hline & $\beta(\mathrm{SE}(\mathrm{B}))$ & $\beta(\mathrm{SE}(\mathrm{B}))$ & $\beta(\mathrm{SE}(\mathrm{B}))$ & $\beta(\mathrm{SE}(\mathrm{B}))$ & $\beta(\mathrm{SE}(\mathrm{B}))$ & $\beta(\mathrm{SE}(\mathrm{B}))$ \\
\hline \multicolumn{7}{|l|}{ Control variables } \\
\hline Sex & $-0.15(0.27)$ & $-0.18(0.28)$ & $-0.05(0.26)$ & $-0.10(0.25)$ & $-0.13(0.26)$ & $-0.20 *(0.27)$ \\
\hline Age & $0.03(0.13)$ & $0.06(0.13)$ & $-0.04(0.13)$ & $0.02(0.12)$ & $-0.13(0.13)$ & $-0.08(0.13)$ \\
\hline \multicolumn{7}{|l|}{ Independent variables } \\
\hline Extraversion & & $0.04(0.10)$ & & $-0.09(0.09)$ & & $-0.05(0.09)$ \\
\hline Emotional Stability & & $-0.09(0.10)$ & & $-0.08(0.09)$ & & $0.07(0.09)$ \\
\hline Openness to Experience & & $-0.22(0.12)$ & & $-0.22 *(0.11)$ & & $-0.20(0.12)$ \\
\hline Agreeableness & & $0.03(0.11)$ & & $-0.13(0.10)$ & & $-0.16(0.10)$ \\
\hline Conscientiousness & & $-0.06(0.09)$ & & $0.26^{* *}(0.09)$ & & $0.04(0.09)$ \\
\hline $\mathrm{F}$ & 1.22 & 1.32 & 0.19 & $2.45^{*}$ & 1.78 & 1.65 \\
\hline $\mathrm{R}^{2}$ & 0.02 & 0.09 & 0.004 & 0.15 & 0.03 & 0.11 \\
\hline Adj. $R^{2}$ & 0.004 & 0.02 & -0.02 & 0.09 & 0.02 & 0.04 \\
\hline$\Delta R^{2}$ & 0.02 & 0.06 & 0.004 & 0.15 & 0.03 & 0.07 \\
\hline$\Delta \mathrm{F}$ & 1.22 & 1.35 & 0.19 & $3.34 * *$ & 1.78 & 1.58 \\
\hline
\end{tabular}

Note. $N=105$. Standard errors in parentheses. ${ }^{*} p<0.05,{ }^{* *} p<0.01$.

Table 4. Hierarchical regression analyses of The Big Five personality traits as predictors of Secondary Stress Appraisal.

\begin{tabular}{|c|c|c|c|c|c|c|}
\hline \multirow{3}{*}{ VARIABLES } & \multicolumn{2}{|c|}{ Secondary Appraisal (T1) } & \multicolumn{2}{|c|}{ Secondary Appraisal (T2) } & \multicolumn{2}{|c|}{ Secondary Appraisal (T3) } \\
\hline & Model 1 & Model 2 & Model 1 & Model 2 & Model 1 & Model 2 \\
\hline & $\beta(\mathrm{SE}(\mathrm{B}))$ & $\beta(\mathrm{SE}(\mathrm{B}))$ & $\beta(\mathrm{SE}(\mathrm{B}))$ & $\beta(\mathrm{SE}(\mathrm{B}))$ & $\beta(\mathrm{SE}(\mathrm{B}))$ & $\beta(\mathrm{SE}(\mathrm{B}))$ \\
\hline \multicolumn{7}{|l|}{ Control variables } \\
\hline Sex & $0.16(0.27)$ & $0.15(0.27)$ & $-0.05(0.24)$ & $-0.03(0.25)$ & $-0.11(0.28)$ & $-0.15(0.28)$ \\
\hline Age & $0.17(0.13)$ & $0.14(0.13)$ & $0.25^{* *}(0.12)$ & $0.24 *(0.12)$ & $0.19(0.14)$ & $0.20 *(0.13)$ \\
\hline \multicolumn{7}{|l|}{ Independent variables } \\
\hline Extraversion & & $-0.19(0.10)$ & & $0.02(0.09)$ & & $-0.27 *(0.10)$ \\
\hline Emotional Stability & & $0.25 *(0.10)$ & & $0.08(0.09)$ & & $0.13(0.10)$ \\
\hline Openness to Experience & & $0.12(0.12)$ & & $0.13(0.11)$ & & $-0.08(0.12)$ \\
\hline Agreeableness & & $0.01(0.11)$ & & $-0.08(0.10)$ & & $0.02(0.11)$ \\
\hline Conscientiousness & & $0.16(0.09)$ & & $0.03(0.08)$ & & $0.20 *(0.10)$ \\
\hline $\mathrm{F}$ & 2.79 & $2.51 *$ & $3.56 *$ & 1.57 & 2.45 & $2.32 *$ \\
\hline $\mathrm{R}^{2}$ & 0.05 & 0.15 & 0.07 & 0.10 & 0.05 & 0.14 \\
\hline Adj. $R^{2}$ & 0.03 & 0.09 & 0.05 & 0.04 & 0.03 & 0.08 \\
\hline$\Delta \mathrm{R}^{2}$ & 0.05 & 0.10 & $0.07^{*}$ & 0.04 & 0.05 & 0.10 \\
\hline$\Delta \mathrm{F}$ & 2.79 & $2.33 *$ & $3.54 *$ & 0.78 & 2.45 & 2.20 \\
\hline
\end{tabular}

Note. $N=105$. Standard errors in parentheses. ${ }^{*} p<0.05,{ }^{* *} p<0.01$.

\section{Discussion}

The present study concerns the effects of Big Five personality traits on stress in light of the transactional theory of stress. The results show that emotional stability is significant for secondary appraisal of anticipated stress. It means that persons who are not susceptible to experiencing negative emotional states expect to cope well while working with a robot. The reason for this might be the fact that lack of negative emotions is related to an increase in adaptability to the environment [25]. Contrary to neurotic persons, emotionally stable individuals recognise the value of available resources adequate to cope with stress [29].

The results also show that openness to experience is a negative predictor of primary stress appraisal. It may be related to the requirement of creativity in work with a robot [41]. Persons with high openness 
to experience are characterised by cognitive curiosity, tolerance for novelty, and willingness to gather new experiences [10]. For this reason, they rarely assess a new situation as stressful. Then, the results suggest that conscientiousness is a positive predictor of primary stress appraisal. Thus, it may be assumed that individuals characterised by reliability, conscientiousness, and fear of making mistakes react with stress in situations requiring them to meet high standards set for their own work [25,32].

The analysis revealed that, after 12 weeks of working with a robot, age and conscientiousness are positive predictors of secondary stress appraisal and extraversion is its negative predictor. It means that the ability to cope with stress is evaluated higher by older, more conscientious, and introverted people. Thus, an increased sense of coping may result from one's competences acquired with experience. Moreover, conscientious persons, apart from competence, are characterised by prudence and dutifulness [16,31], which are foundations for direct remedial actions. Finally, introverted persons working with a robot accept responsibility for the situation and trust themselves and their own abilities to cope well, without seeking support from their co-workers. This is significant because in HRI, contact with co-workers may be naturally limited.

This multi-wave research is a valuable contribution to studies on the human-robot relationship. Nonetheless, it has some limitations. The first of them is the size of the sample. Despite the fact that this study was conducted on a sample bigger than it was in the studies on stress in HRI conducted so far, in order to enable generalisation of the results, replication of the study in a more sizeable group is necessary. Secondly, the group consisted of students, mainly of men. Hence, future studies on stress in human-robot interaction should involve employees who work with robots on a daily basis and for longer periods of time in order to study the dynamics and long-term consequences of work stress. The third limitation results from the assumption in the theory of traits that it is possible to replace one consistent model of personality traits with another consistent model [42]. The subjects are young adults, whose trait pattern is undergoing the process of stabilization [43]. For these reasons, conclusions from the study should be drawn cautiously if one aims to discuss women's and elderly persons' functioning in interactions with robots. The last limitation stems from the conceptual framework of the study in which we focused exclusively on the direct relationship between The Big Five personality traits and psychological stress. Although this was purposely done due to the infancy of the studies on psychological stress among humans collaborating with robots, further research should focus on a broader range of factors relevant to human-robot interaction, including potential mediators and moderators. Therefore, future explorations should include other personality traits (e.g., core self-evaluations, the propensity to trust, or resiliency), attitudes towards robots, and state-like variables (e.g., positive and negative emotions or trust towards robots). These constructs could be examined as having the potential to explain the mechanism of the relationship between personality traits and psychological stress among humans who operate robots.

Author Contributions: Conceptualization, A.P., M.D., and M.P.; methodology, A.P., and M.P.; formal analysis, M.P.; investigation, A.P. and M.D.; resources, A.P., M.D., and M.P.; data curation, M.D. and M.P.; writing-original draft preparation, A.P., M.D., and M.P.; visualization, M.P.; supervision, M.T.; project administration, A.P., M.D., and A.T.; funding acquisition, M.D. All authors have read and agreed to the published version of the manuscript.

Funding: The publication is financed within the framework of the programme titled "Dialogue", introduced by the Minister of Science and Higher Education between 2016-2019.

Conflicts of Interest: The authors declare no conflict of interest.

\section{References}

1. Bausys, R.; Cavallaro, F.; Semenas, R. Application of sustainability principles for harsh environment exploration by autonomous robot. Sustainability 2019, 11, 2518. [CrossRef]

2. Gualtieri, L.; Palomba, I.; Merati, F.A.; Rauch, E.; Vidoni, R. Design of human-centered collaborative assembly workstations for the improvement of operators' physical ergonomics and production efficiency: A case study. Sustainability 2020, 12, 3606. [CrossRef] 
3. Dekker, F.; Salomons, A.M.; Waal, J.V. Fear of robots at work: The role of economic self-interest. Socio-Econ. Rev. 2017, 15, 539-562.

4. Lasota, P.A.; Fong, T.; Shah, J.A. A survey of methods for safe human-robot interaction. Found. Trends Rob. 2017, 5, 261-349. [CrossRef]

5. Inoue, K.; Nonaka, S.; Ujiie, Y.; Takubo, T.; Arai, T. Comparison of human psychology for real and virtual mobile manipulators. In Proceedings of the IEEE International Workshop on Robot and Human Interactive Communication, RO-MAN, Nashville, TN, USA, 13-15 August 2005; pp. 73-78.

6. Mumm, J.; Mutlu, B. Human-robot proxemics: Physical and psychological distancing in human-robot interaction. In Proceedings of the 6th International Conference on Human-robot Interaction-HRI'11, Lausanne, Switzerland, 6-9 March 2011. [CrossRef]

7. Taniguchi, K.; Nishikawa, A.; Sugino, T.; Aoyagi, S.; Sekimoto, M.; Takiguchi, S.; Okada, K.; Monden, M.; Miyazaki, F. Method for objectively evaluating psychological stress resulting when humans interact with robots. In Advances in Human-Robot Interaction; Kulyukin, V.A., Ed.; InTech: Vukovar, Croatia, 2009; pp. 141-164.

8. Kulić, D.; Croft, E. Physiological and subjective responses to articulated robot motion. Robotica 2007, 25, 13-27. [CrossRef]

9. Aldinhas Ferreira, M.I. Technological development and well-being. In Intelligent Systems, Control and Automation: Science and Engineering, Robotics and Well-Being; Aldinhas Ferreira, M.I., Sequeira, J.S., Virk, G.S., Tokhi, M.O., Kadar, E.E., Eds.; Springer: Cham, Switzerland, 2019; Volume 95, pp. 1-9.

10. Costa, P.T.; McCrae, R.R. Revised NEO personality inventory and NEO five factor inventory. In Professional Manual; Psychological Assessment Resources: Odessa, FL, USA, 1992.

11. Lazarus, R.S.; Folkman, S. Stress, Appraisal, and Coping; Springer: New York, NY, USA, 1984.

12. Bartneck, C.; Kulić, D.; Croft, E.; Zoghbi, S. Measurement instruments for the anthropomorphism, animacy, likeability, perceived intelligence, and perceived safety of robots. Int. J. Soc. Robot. 2009, 1, 71-81. [CrossRef]

13. Penley, J.A.; Tomaka, J. Associations among the big five, emotional responses, and coping with acute stress. Pers Indiv. Differ. 2002, 32, 1215-1228. [CrossRef]

14. Gaab, J.; Rohleder, N.; Nater, U.M.; Ehlert, U. Psychological determinants of the cortisol stress response: The role of anticipatory cognitive appraisal. Psychoneuroendocrinology 2005, 30, 599-610. [CrossRef]

15. Kaiseler, M.; Polman, R.C.J.; Nicholls, A.R. Effects of the big five personality dimensions on appraisal coping, and coping effectiveness in sport. Eur. J. Sport Sci. 2012, 12, 62-72. [CrossRef]

16. Vollrath, M. Personality and stress. Scand. J. Psychol. 2001, 42, 335-347. [CrossRef]

17. Bolger, N.; Zuckerman, A. A framework for studying personality in the stress process. J. Pers. Soc. Psychol. 1995, 69, 890-902. [CrossRef] [PubMed]

18. Leger, K.A.; Charles, S.T.; Turiano, N.A.; Almeida, D.M. Personality and stressor-related affect. J. Pers. Soc. Psychol. 2016, 111, 917-928. [CrossRef] [PubMed]

19. Suls, J.; Martin, R. The daily life of the garden-variety neurotic: Reactivity, stressor exposure, mood spillover, and maladaptive coping. J. Pers. 2005, 73, 1485-1510. [CrossRef] [PubMed]

20. Pervin, L.A.; John, O.P. Osobowość: Teoria i Badania [Personality: Theory and Research]; Wydawnictwo Uniwersytetu Jagiellońskiego: Krakow, Poland, 2002.

21. Costa, P.T., Jr.; McCrae, R.R.; Dye, D.A. Facet scales for agreeableness and conscientiousness: A revision of the NEO personality inventory. Person. Individ. Diff. 1992, 12, 887-898. [CrossRef]

22. Connor-Smith, J.K.; Flachsbart, C. Relations between personality and coping: A meta-analysis. J. Pers. Soc. Psychol. 2007, 93, 1080. [CrossRef]

23. John, O.P.; Srivastava, S. The big five trait taxonomy: History, measurement, and theoretical perspectives. In Handbook of Personality: Theory and Research, Part 2, 2nd ed.; Pervin, L.A., John, O.P., Eds.; The Guilford Press: New York, NY, USA, 1999; pp. 102-138.

24. Robert, L.P., Jr.; Alahmad, R.; Esterwood, E.; Kim, S.; You, S.; Zhang, Q. A review of personality in human-robot interactions. Found. Trends Inf. Syst. 2020, 4, 107-212. [CrossRef]

25. Zawadzki, B.; Strelau, J.; Szczepaniak, P.; Śliwińska, M. Inwentarz Osobowości NEO-FFI Costy I McCrea. [The Polish Adaptation of Personality Inventory (NEO-FFI) Costa and McCrae Manual]; Pracownia Testów Psychologicznych: Warsaw, Poland, 2007.

26. Lee-Baggley, D.; Preece, M.; DeLongis, A. Coping with interpersonal stress: Role of big five traits. J. Pers. 2005, 74, 1141-1180. [CrossRef] 
27. O'Brien, T.B.; DeLongis, A. The interactional context of problem-, emotion-, and relationship-focused coping: The role of the big five personality factors. J. Pers. 1996, 64, 775-813. [CrossRef]

28. Schneider, T.R. The role of neuroticism on psychological and physiological stress responses. J. Exp. Soc. Psychol. 2004, 40, 795-804. [CrossRef]

29. Gunthert, K.C.; Cohen, L.H.; Armeli, S. The role of neuroticism in daily stress and coping. J. Pers. Soc. Psychol. 1999, 77, 1087. [CrossRef]

30. Asendorpf, J.B.; Van Aken, M.A. Personality-relationship transaction in adolescence: Core versus surface personality characteristics. J. Pers. 2003, 71, 629-666. [CrossRef] [PubMed]

31. Carver, C.S.; Connor-Smith, J. Personality and coping. Annu. Rev. Psychol. 2010, 61, 679-704. [CrossRef] [PubMed]

32. Włodarczyk, D.; Obacz, W. Perfectionism, selected demographic and job characteristics as predictors of burnout in operating suite nurses. Medycyna Pracy 2013, 64, 761-773. [CrossRef]

33. Nonaka, S.; Inoue, K.; Arai, T.; Mae, Y. Evaluation of human sense of security for coexisting robots using virtual reality. 1st report: Evaluation of pick and place motion of humanoid robots. In Proceedings of the IEEE International Conference on Robotics and Automation, New Orleans, LA, USA, 26 April-1 May 2004.

34. Kulic, D.; Croft, E.A. Anxiety detection during human-robot interaction. In Proceedings of the IEEE/RSJ International Conference on Intelligent Robots and Systems, Edmonton, AB, Canada, 2-6 August 2005; pp. 616-621.

35. Arai, T.; Kato, R.; Fujita, M. Assessment of operator stress induced by robot collaboration in assembly. CIRP Ann. 2010, 59, 5-8. [CrossRef]

36. Takayama, L.; Pantofaru, C. Influences on proxemic behaviors in human-robot interaction. In Proceedings of the IEEE/RSJ International Conference on Intelligent Robots and Systems 2009, St. Louis, MO, USA, 10-15 October 2009; pp. 5495-5502.

37. Clark, L.A.; Watson, D. Constructing validity: Basic issues in objective scale development. Psychol. Assess. 1995, 7, 309-319. [CrossRef]

38. Sorokowska, A.; Słowińska, A.; Zbieg, A.; Sorokowski, P. Polska Adaptacja Testu Ten Item Personality Inventory (TIPI) - TIPI-PL_Wersja Standardowa i Internetowa [Polish Adaptation of Ten Item Personality Inventory (TIPI)_TIPI-Pl—Standard and Internet Versions]; WrocLab: Wroclaw, Poland, 2014.

39. Gosling, S.D.; Rentfrow, P.J.; Swann, W.B. A very brief measure of the big-five personality domains. J. Res. Pers. 2003, 37, 504-528. [CrossRef]

40. Field, A. Discovering Statistics Using IBM SPSS Statistics, 5th ed.; SAGE Publications: London, UK, 2018.

41. Wisskirchen, G.; Biacabe, B.T.; Bormann, U.; Muntz, A.; Niehaus, G.; Soler, G.J.; von Brauchitsch, B. Artificial Intelligence and Robotics and Their Impact on the Workplace; IBA Global Employment Institute: London, UK, 2017.

42. McCrae, R.R.; Costa, P.T. Osobowość Dorosłego Człowieka. Perspektywa Teorii Pięcioczynnikowej [Personality in Adulthood: A Five-Factor Theory Perspective], 1st ed.; WAM: Krakow, Poland, 2005; p. 308.

43. Luo, J.; Derringer, J.; Briley, D.A.; Roberts, B.W. Genetic and environmental pathways underlying personality traits and perceived stress: Concurrent and longitudinal twin studies. Eur. J. Pers. 2017, 31, 614-629. [CrossRef]

(C) 2020 by the authors. Licensee MDPI, Basel, Switzerland. This article is an open access article distributed under the terms and conditions of the Creative Commons Attribution (CC BY) license (http://creativecommons.org/licenses/by/4.0/). 